
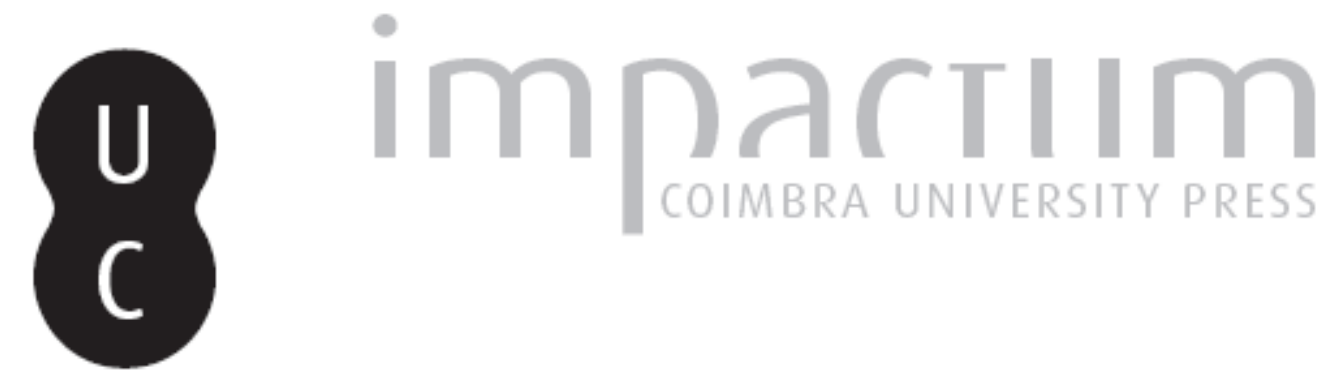

II Duce à secretária de Salazar: lição sobre o lugar da história no Nuovo Stato

Autor(es): Correia, Luís Miguel

Publicado por: Imprensa da Universidade de Coimbra

URL persistente:

URI:http://hdl.handle.net/10316.2/44967

DOI:

DOI:https://doi.org/10.14195/0870-8584_12_4

Accessed : $\quad$ 26-Apr-2023 13:58:35

A navegação consulta e descarregamento dos títulos inseridos nas Bibliotecas Digitais UC Digitalis, UC Pombalina e UC Impactum, pressupõem a aceitação plena e sem reservas dos Termos e Condições de Uso destas Bibliotecas Digitais, disponíveis em https://digitalis.uc.pt/pt-pt/termos.

Conforme exposto nos referidos Termos e Condições de Uso, o descarregamento de títulos de acesso restrito requer uma licença válida de autorização devendo o utilizador aceder ao(s) documento(s) a partir de um endereço de IP da instituição detentora da supramencionada licença.

Ao utilizador é apenas permitido o descarregamento para uso pessoal, pelo que o emprego do(s) título(s) descarregado(s) para outro fim, designadamente comercial, carece de autorização do respetivo autor ou editor da obra.

Na medida em que todas as obras da UC Digitalis se encontram protegidas pelo Código do Direito de Autor e Direitos Conexos e demais legislação aplicável, toda a cópia, parcial ou total, deste documento, nos casos em que é legalmente admitida, deverá conter ou fazer-se acompanhar por este aviso. 


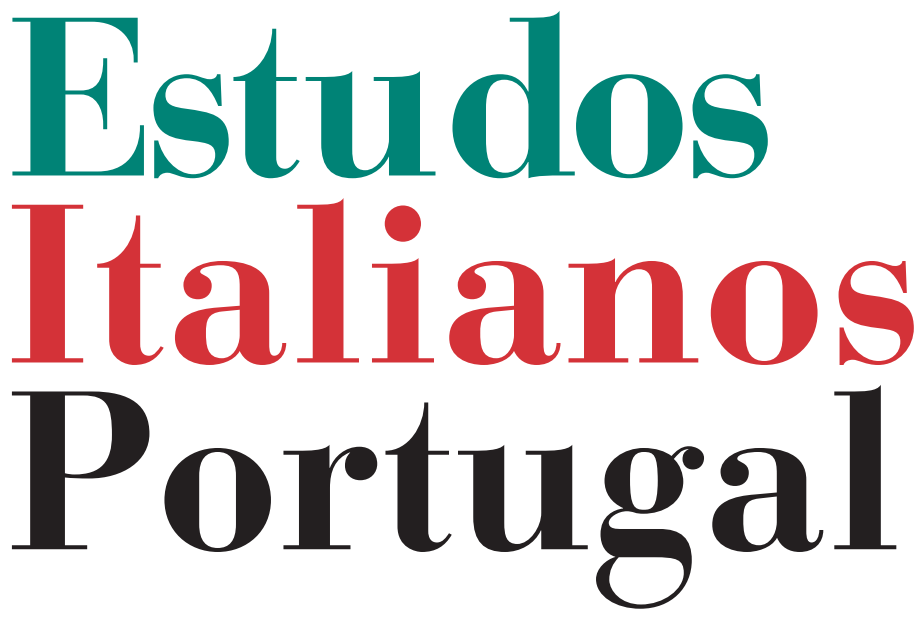

Instituto

Italiano

de Cultura

de Lisboa

Nova Série

No 12

2017 


\section{IL DUCE À SECRETÁRIA DE SALAZAR. LIÇÃO SOBRE O LUGAR DA HISTÓRIA NO NUOVO STATO}

\section{Luís Miguel CorReia*}

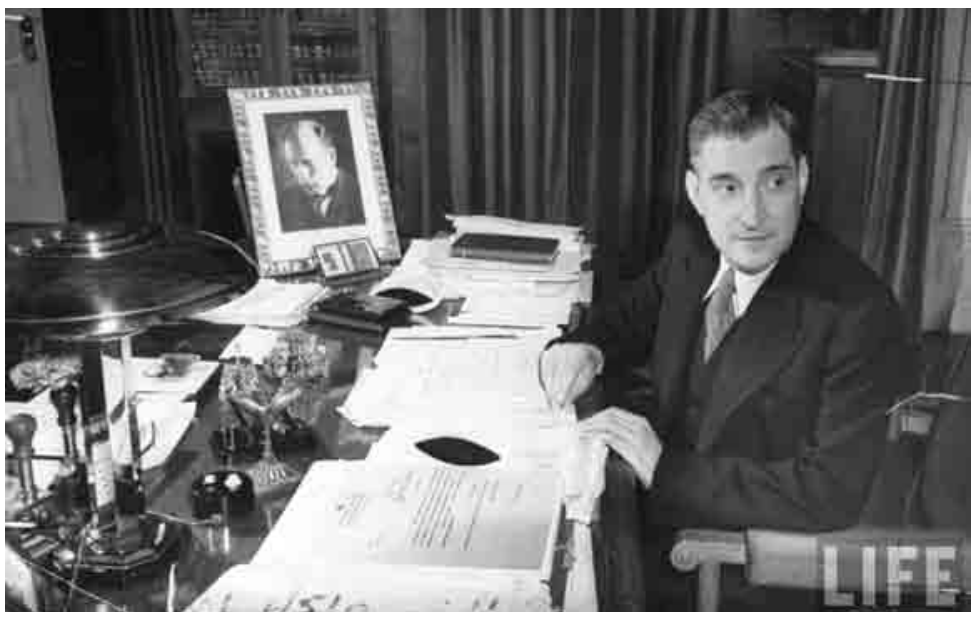

Fig. 1 Oliveira Salazar no seu gabinete com o retrato de Benito Mussolini sobre a secretária. Fotografia de Bernard Hoffman para Life Magazine, 1940.

A InSTRUmentalizaÇÃo dos monumentos como objectos de controlo e de poder foi utilizada em Itália por Benito Mussolini, Il Duce, especialmente ao servir-se dos vestígios da Roma Antiga e do seu restauro como importantes ferramen-

* Luís Miguel Correia é Professor Auxiliar no Departamento de Arquitectura da Faculdade de Ciências e Tecnologia da Universidade de Coimbra e membro do Centro de Estudos Interdisciplinares do Século XX (CEIS20). Vota parcialmente a sua investigação à relação que os monumentos nacionais, desde meados de oitocentos, vêm mantendo com o território, a paisagem e uma certa ideia de identidade nacional. lcorreia@darq.uc.pt 
tas de acção e propaganda política. Com recurso obsessivo ao mito dos antigos romanos, o ditador italiano que, diga-se, se via como legítimo sucessor dos lendários Césares, pretendia "recolocar o presente conturbado no imaginário de uma continuidade com um passado tranquilizador, e sobretudo esquecer o passado recente", afirma Marc Guillaume em La politique du patrimoine, cuja tradução portuguesa compulsámos (Guillaume 2003: 142-143). Na ideia de romanidade, peça central da ideologia e oratória do fascismo em Itália, encontrava-se implícita uma vontade de instruir uma representação expurgada de séculos de decadência e influências estrangeiras. Nas palavras do mesmo autor, citando a obra La freccia ferma. Tre tentativi di annullare il tempo, de Elvio Fachinelli, esta ficção ia talvez "ao encontro de uma certa sensibilidade popular, que lhe conferia eficácia política" (Guillaume 2003: 142).

Em consonância com Paolo Sica em Storia dell'urbanistica. Il Novecento, cuja edição espanhola adoptaremos, à capital, Roma, ficaria destinado um papel indispensável na afirmação dos propósitos do fascismo italiano (Sica 1981). Presumivelmente, seria nesta cidade que se assistiria aos episódios mais grandiosos e convincentes da estratégia ideológica gizada pelo Duce, constituindo, por este motivo, um exemplo para as demais.

Assim, ao serviço do imaginário do poder e, alegadamente, ao abrigo da sempre consensual conservação histórica, Il Duce impôs à capital uma faustosa reforma que teve como objectivo não só o restabelecimento das ruínas da Roma Imperial, como o Capitólio, os Fóruns, o Túmulo de Augusto ou o Coliseu, mas, sobretudo, a consumação solene e simbólica da relação entre o Stato Nuovo e a romanidade. Por outras palavras, desejou legitimar e associar a Roma Fascista à Roma dos Césares. A cidade seria dessarte o majestoso palco, enquanto expressão urbana, do programa político então sonhado. Para Paolo Sica, 
Valorizar los restos de la primera Roma con los criterios urbanísticos de la Roma fascista, quitando de en medio todo lo que obstaculice la realización de las escenografías monumentales queridas por el régimen, constituye el tema central de las transformaciones de la capital [...]

(Sica 1981: 403)

Sobre as intençôes de Il Duce, atente-se em dois dos seus discursos. O primeiro foi pronunciado no Campidoglio, em Roma, no dia 21 de Abril de 1924, por ocasião da celebração do aniversário da fundação de Roma, ocasião em que seria agraciado com a cittadinanza romana. A respeito da história de Roma, desde a antiguidade até à sua época, pronunciarse-ia nos seguintes termos:

Bisogna liberare dalle deturpazioni mediocri tutta la Roma Antica, ma accanto all'antica ed alla medioevale, bisogna creare la monumentale Roma del XX secolo. Roma non può, non deve essere solo una città moderna [...], deve essere una città degna della sua Gloria e questa gloria deve rinnovare incessantemente per tramandarla, come retaggio dell'età fascista, alle generazioni che verranno [...]. Salve Dea Roma! (apud Zagni 2006: 281)

No segundo, proferido a 31 de Dezembro de 1925 no mesmo local, Il Duce advertiria, no caso a propósito da tomada de posse do primeiro Governador de Roma, Filippo Cremonesi:

Tra cinque anni Roma deve apparire meravigliosa a tutte le genti del mondo: vasta, ordinata e potente come fu nei tempi del Primo Imperio di Augusto [...] continuerete a liberare il tronco della grande quercia da tutto ciò che ancora l'aduggia [...] farete largo attorno all'Augusteo, al Teatro Marcello, al Campidoglio, al Pantheon. Tutto ciò che vi crebbe intorno nei secoli della decadenza deve scomparire [...] I monumenti millenari della nostra storia devono giganteggiare nella necessaria solitudine.

(apud Zagni 2006: 281) 
$\mathrm{Na}$ avaliação de Paolo Sica, esta última comunicação é francamente relevante, em particular porque nela dois importantes argumentos sobrevinham como elucidativos da estratégia determinada por Il Duce. Se, por um lado, ela impunha um imponente programa de transformações urbanas a realizar num prazo de cinco anos, por outro lado, associava-lhe, sem equívocos, os princípios políticos e os critérios de intervenção pelos quais se deviam reger as obras de renovação da cidade. Ainda segundo o mesmo autor, os prazos apontados para a materialização da nova Roma não eram de todo exequíveis, mesmo que se perscrutasse vigoroso ritmo de execução do programa fascista.

Contudo, testemunha Paolo Sica, o anúncio destes limites temporais seria determinante por duas ordens de razão: primeiro, porque estimulou de forma directa a elaboração de propostas com vista à renovação funcional e monumental de Roma, situação que, anos mais tarde, estaria na origem da apresentação de um novo plano regulador para a cidade ${ }^{1}$; segundo, porque legitimou e ampliou o programa municipal das obras de libertação e valorização das ruínas romanas, em

${ }^{1}$ Sobre o processo que conduziu à apresentação do Plano Regulador de 1931 para Roma, pode-se consultar igualmente a obra de Paolo Sica. A comissão encarregada da elaboração deste Plano Regulador, constituída em Março de 1930, foi presidida pelo governador Boncompagni Ludovisi e contou com a presença dos arquitectos Brasini, Piacentini, Giovannoni, Bazzani, Calza Bini e Del Bufalo. Tal plano foi entregue ao Duce em 28 de Outubro de 1930 e seria aprovado em Maio do ano seguinte. Em fase posterior, seriam apresentados e aprovados alguns planos particulares, como por exemplo o Piano particolareggiato d'esecuzione della zona interessante la nuova strada da via Cavour al Colosseo, aprovado a 25 de Janeiro de 1932. Numa breve síntese, pode dizer-se que o Plano Regulador de 1931 para Roma seguia a política oficial do regime relativamente ao centro histórico. Deste modo, previa-se um avultado número de demoliçóes com o objectivo de destacar e valorizar as vetustas antiguidades romanas. Como nota Paolo Sica, considerando para o efeito a sequência cronológica das obras executadas, este plano em nada perturbou o andamento dos trabalhos de libertação destas estruturas, iniciadas no ano de 1924, como antes se referiu. 
marcha desde de $1924^{2}$. Quanto ao espírito do programa, ficava preciso nestes discursos que tudo quanto pudesse obscurecer os monumenti millenari deveria ser demolido. Para Il Duce, somente com a efectiva eliminação das construçóes cuidadas espúrias, vestígios de séculos de decadência, poderiam os monumentos finalmente emergir na necessaria solitudine, agora símbolos da querida romanidade. Em nossa consideração, à valorização das ruínas de Roma também ficaram ligadas duas proeminentes concepçôes, a saber: um modelo de comportamento e uma certa ideia de identidade nacional.

Com vista ao cumprimento deste projecto político, realizaram-se durante alguns anos obras de grande vulto, sobretudo de tendência monumental. Estas intervençōes tiveram por finalidade não apenas a libertação e a regularização das áreas históricas da velha Roma, onde se localiz(av)am os despojos romanos, mas, ao mesmo tempo, a abertura da cidade à vida moderna. Em Roads and Ruins. The Symbolic Landscape of Fascist Rome, Paul Baxa estima que decerto Il Duce ambicionava uma Roma moderna, todavia "the world of the machine was to find a home in Rome while at the same time respecting the city as a work of art" (Baxa 2010: 56). A concretização deste empreendimento provirá, neste contexto, do isolamento das construçôes singulares, do rasgamento de novas e amplas vias de comunicação e, com certeza, do sacrifício de extensos bairros antigos, nos últimos dois casos sob pretextos higienistas e modernizadores.

Como depreende Marc Guillaume, à sobrevalorização destas estruturas milenares que, em simultâneo, simbolizavam as grandezas da Antiguidade e do Nuovo Stato fascista, contrapunha-se a inexistência de um plano urbanístico coerente que fizesse face aos verdadeiros problemas da cidade, quais

\footnotetext{
${ }^{2}$ Segundo a cronologia apresentada por Paolo Sica, as obras começadas em 1924 tiveram como fim a desobstrução da zona compreendida entre o monumento a Vittorio Emanuele II e o Coliseu, com o intuito de pôr à luz do dia o Fórum de Trajano, o Fórum de César e o Fórum de Augusto.
} 
eram a demografia, a circulação de veículos, a deslocação das classes populares para a periferia e o agravamento da especulação fundiária. Em suma, conferiam-se a estas áreas históricas e a estes monumentos papéis próprios, se bem que equitativamente influentes na vivência quotidiana da nova Roma desenhada por Il Duce. Esta representação supostamente garantia continuidade e concertava harmonia entre o momento da história eleito e o projecto político criado, isto é, entre o antes e o depois. À laia de uma qualquer encenação, Il Duce, na qualidade de realizador, mais não fez do que envolver o povo e emocioná-lo com o seu argumento, creditando a alguns dos seus principais protagonistas, os monumentos, o discurso incontroverso da verdade, ainda hoje tão em voga.

Uma das intervençóes mais proeminentes desta campanha ocorreu com a abertura da Via dell'Impero, actualmente Via dei Fori Imperiali. Antes designada por Via dei Monti, a Via dell'Impero foi inaugurada em 28 de Outubro de 1932, aquando das comemorações do décimo aniversário da Marcia su Roma. Trata-se de uma extensa avenida que atravessa os fóruns e liga de forma rectilínea a Praça de Veneza e o Coliseu ${ }^{3}$. A sua concretização fez-se à custa de violentas transformações no subsolo, no caso, em continuidade com as extensas escavações arqueológicas já realizadas a partir de 1924, da eliminação de numerosos edifícios, alguns de relevante interesse histórico e artístico, e, em consequência, do despejo de várias famílias das suas casas. Foi sob a perspectiva triunfante da nova Via dell'Impero que se avistaram as imagens mais frequentes da propaganda fascista.

Para o regime, a Via dell'Impero representava, finalmente, a cobiçada aliança entre o passado glorioso dos Césares e a ac-

\footnotetext{
${ }^{3}$ Considerando a abertura desta nova via urbana junto aos fóruns, no Piano particolareggiato d'esecuzione della zona interessante la nuova strada da via Cavour al Colosseo descobrem-se, pintados a amarelo, os edifícios a demolir. A ideia da Via dell'Impero surge alguns anos antes da apresentação do citado Plano Regulador de 1931, então sob proposta de Corrado Ricci.
} 
ção heróica do seu líder. À semelhança dos antigos chefes romanos, Il Duce impunha, com gesto autoritário e pomposo, uma nova ordem no tecido urbano da capital, reconciliando, lado a lado, ilustres vestígios romanos e a modernidade pretendida. Conforme Antonio Muñoz, em La via dell'Impero e la via del Mare, de par com Corrado Ricci, um dos principais responsáveis pelas obras praticadas em Roma,

[1]'idea geniale di congiungere Piazza Venezia con il Colosseo e con la Via del Mare, per mezzo di due ampie strade, possibilmente tracciate secondo la linea più breve, non fu ispirata soltanto da ragioni estetiche, ma anche specialmente da ragioni pratiche. Una comunicazione diretta tra il centro e i quartieri del Celio dell'Esquilino e del Laterano mancava finora, perché la maggiore arteria, la via Cavour andava a morire contro la barriera del Foro Romano, e si perdeva in un dedalo di viuzze. [...] Questa zona di verde costituisce a fianco della via dell'Impero una specie di passeggiata archeologica, dove il visitatore potrà sostare nell'ammirazione degli antichi monumenti, in piena tranquillità, mentre sulla via principale si svolgerà il traffico rapido e vivace. E quale mirabile quinta delimita la scena!

(Muñoz 1932: 521, 529)

Já em Outubro de 1934, em entrevista concedida a António Ferro em Roma ${ }^{4}$, Il Duce veio a reconhecer a importância da intervenção entretanto realizada. Num fugaz encontro, de vera e profunda cumplicidade entre ambos, interpelaria o entrevistador sobre a nuova Roma encontrada. António Ferro rejubilou então com o que descortinara, respondendo-lhe que pudera afinal contemplar "outra cidade", um "milagre", cuja eminente realização seguramente tornara "activas, dinâmicas, as ruínas de Roma" (Ferro [1941]: 185). Com um "sorriso de triunfo", Il Duce continuaria a inquirir o seu convidado:

${ }^{4}$ Trata-se da terceira entrevista que António Ferro fez a Il Duce. As outras duas ocorreram nos anos de 1923 e de 1926. Esta reportagem está publicada em Homens e multidóes. 
Roma [continua] comum a todas as épocas, a todas as civilizações! Viu como os foros imperiais se enquadram bem na urbanização moderna, na rua de 'hoje'?! Viu como as ruínas vêem passar, sem espanto, os milhares de automóveis que buzinam, de sol a sol, na Via dell'Impero? (Ferro [1941]: 185)

$\mathrm{Na}$ verdade, António Ferro tinha-o visto. Antes do encontro com Il Duce, passeara pela Via dell'Impero e já anuíra que não conhecia outra rua no mundo "onde o passado [fizesse] menos cerimónia com o presente", acrescentando que "tudo pare[cia] de ontem, mais ainda, tudo pare[cia] de hoje!... 'Ruínas ou primeiras pedras?”" (Ferro [1941]: 172), notava. Aclamava a "parada esmagadora de foros imperiais" e as obras empreendidas no circo romano "outrora escondido, diminuído, por vários becos e vielas, que tornavam difícil o seu acesso, hoje completamente descoberto, severa apoteose da rua imortal [...] cortada por automóveis, geometricamente ajardinada e arborizada" (Ferro [1941]: 172-173). Contemplando um cartaz de propaganda à data exibido, António Ferro terminava, exaltando: "debruça[do] sobre os foros imperiais desenterrados, [era] esse gesto do Duce que [via] sempre, o gesto da picareta libertadora, o gesto hercúleo de quem soube restituir a Roma a sua eternidade" (Ferro [1941]: 174).

Para Marc Guillaume, "todos os países [viveram] uma política deste tipo", ou seja, viram os monumentos "transformados em operadores ideológicos eficazes" (Guillaume 2003: 143). Na verdade, não há nação sem monumentos nacionais e, inevitavelmente, não há passado sem eles: um monumento não pode mentir. Em complemento desta última alegação, que corroboramos, Marc Guillaume conclui que a instrumentalização-encenação, expurgada de todas as referências qualificadas de decadentes, pode servir para, peremptoriamente, "consolidar todos os mitos do poder: a sua legitimidade, a sua grandeza reencontrada, até mesmo a sua dimensão fascista" (Guillaume 2003: 144). Assim, a apro- 
priação que o Stato Nuovo de Il Duce empreendeu sobre as ruínas de Roma pode ser estimada como um bom modelo de ver os restos históricos, matéria disponível e de franca manipulação, ao serviço desta arqueologia de raiz política.

Em Portugal, o Estado Novo, encabeçado por Oliveira Salazar, viria a perfilhar um horizonte triunfal similar ao do fascismo italiano, liderado por Il Duce. Tal como sucedeu com as ruínas romanas, os castelos portugueses, pela sua natureza morta, viriam a ser protagonistas das mais destacadas acções de propaganda do Salazarismo, veiculando a sua monumental presença no território à mensagem do poder político instituído.

De acordo com Estados Novos, Estado Novo. Ensaios de história política e cultural de Luís Reis Torgal (2009), o habitual paralelismo que se estabelece entre os regimes italiano e português é legítimo e descobre a sua principal justificação na proximidade dos seus princípios e realizaçôes, à qual não é indiferente a estreita relação pessoal existente entre os respectivos chefes de Governo. De facto, Oliveira Salazar e Il Duce respeitavam-se e admiravam-se reciprocamente. Uma cumplicidade que, a título de exemplo, se pode vislumbrar na figura que inaugura este artigo onde, qual alter ego do Professor de Coimbra, Il Duce parece participar simbolicamente na gestão diária do Império Português. Neste sentido se compreende que, aquando da entrevista a António Ferro, lhe confiasse a seguinte mensagem: "Diga ao Dr. Salazar que conheço e tenho seguido a sua obra, que sei medir bem a sua estatura e que o admiro muito" (Ferro [1941]: 181). Porém, Oliveira Salazar detinha como estratégia diferenciar o quadro nacional de qualquer outro, inclusive o italiano, com o qual admitia algumas afinidades ideológicas. Na sua óptica, tratava-se de (re)afirmar a nossa singularidade enquanto portugueses que descobrem na História do seu País um passado comum e, igualmente, a possibilidade de fabricar um presente e um futuro a ela associados. 
Por conseguinte, construir-se-ia em Portugal à época do Estado Novo um cenário ideológico sobretudo assente na narrativa histórica em torno do período medieval ligado às lutas pela independência e consolidação territorial, conquanto se conferisse idêntica importância a outras eras que certificassem momentos de glória da Nação, quais foram, v.g., os descobrimentos e a restauração da independência.

Os monumentos seriam usados como meios distintos ao serviço da produção de uma política de verdade, edificada sobre uma atmosfera sonhada que, numa sequência temporal pré-determinada, privilegiava a crença histórica, em detrimento da historicidade, como forma de legitimar a grandiosidade dos seus incensuráveis, princípios e realizaçôes. Em suma, os monumentos na mira de obras de conservação e restauro foram eleitos de sorte que a dimensão histórica do seu passado na maioria das situações se sobrepôs à consideração de qualquer propriedade arquitectónica ou detalhe artístico: aos monumentos nacionais deviam corresponder episódios singulares e figuras heróicas da História de Portugal.

Sempre sujeita às restriçóes que este ponto de vista implica(va), a generalidade das obras devia pautar-se por uma filosofia de reintegração e integridade arquitectónica e artística que, desde que possível, garantisse a reposição dos monumentos no seu presumido estado primitivo, expurgando-os de todos os acrescentos realizados em épocas posteriores, por forma a que aparentassem uma imagem consentânea com o respectivo tempo histórico. Creditavam-se a memória e a herança do passado à prova que os monumentos por si próprios conseguiam autenticar, encontrando-se o documento, o retrato do objecto, dependente desta circunstância. Perante este enquadramento ideológico, os castelos vieram naturalmente a emergir como produtos de interesse maior, já que se constituíam sinais distintivos da defesa e consolidação das fronteiras territoriais do País, fontes de lendas gloriosas. 
Sobre o crédito imputado a estas estruturas militares, as palavras de Henrique Gomes da Silva, director-geral da Direcção-Geral dos Edifícios e Monumentos Nacionais (DGEMN), espelham as intenções do Estado Novo e os propósitos das campanhas que se cumpririam nos anos seguintes. Porém, foram várias e persistentes as dificuldades com que aquele se confrontou na execução das primeiras obras nos castelos, nomeadamente as provocadas pelo Ministério da Guerra, o qual obrigava à submissão e aprovação da Direcção da Arma de Engenharia as intervenções que neles se pretendia levar a cabo.

Por isso, o director-geral, ainda num estado embrionário do organismo que dirigia, enviou uma comunicação ao Presidente do Conselho de Arte e Arqueologia da 1. ${ }^{\text {a Circuns- }}$ crição, em 4 de Abril de 1931, explicitando que considerava tal exigência descabida, por obstaculizar o restauro desses monumentos nacionais, cujas eventuais necessidades militares deviam ser subordinadas ao seu carácter monumental. Numa altura em que as atribuições da DGEMN ainda não estavam inteiramente estatuídas, Henrique Gomes da Silva contestava:

[...] salvo o devido respeito pelas opiniōes alheias, afigura-se-me que tal exigência não tem razão de ser, visto que esses monumentos, apesar de militares não deixam de ser nacionais. Como tais, quaisquer obras a executar neles devem tender a sua conservação ou restauro, isto é, a evitar a sua ruína ou reintegrá-los no seu estilo e arquitectura primitiva e nunca a satisfazer possíveis necessidades militares. Se alguns deles se tornarem precisos para este último fim, não deve ser classificado monumento nacional, mas apenas como edifício militar.

(Silva 1931)

Neste ofício, ficava certificado que os castelos detinham um importante papel no contexto das competências da DGEMN e, concomitantemente, que as obras de conservação e restauro a praticar os deveriam restituir ao seu estilo 
primitivo, impedindo a sua ruína. Assim, descortinamos neste documento do início da década de trinta uma antecipação daquele que é hoje entendido como um dos textos fundadores da doutrina da DGEMN, cuja autoria pertence ao supradito Henrique Gomes da Silva: Monumentos Nacionais. Orientação técnica a seguir no seu restauro (Silva 1935). Os preceitos ideológicos assentidos pela esfera do poder político ao património construído classificado justificavam, per se, o enquadramento das intervenções efectuadas. As diversas campanhas executadas nos castelos comprovaram, principalmente pela sua dimensão e escala, que eles ocuparam um lugar de destaque no processo de instrumentalização da história conduzido pela Ditadura.

$\mathrm{Na}$ recepção ao corpo diplomático sediado em Lisboa, realizada no Castelo de Almourol a 27 de Junho de 1938, Oliveira Salazar com ênfase reiteraria semelhante desígnio a tais objectos representativos de oitocentos anos de independência:

Evocam estas ruínas, com efeito, a coragem e a perseverança desses varōes esforçados da Idade Média, defensores do território da Pátria e da Civilização cristã, que nenhuma força pôde vencer enquanto se conservaram fiéis à sua fé e aos seus ideais, e que só foram substituídos por outros quando falharam na sua missão. Assim acontece sempre, tanto no que respeita a homens como a instituições. Também nós temos de defender as nossas pátrias e as nossas heranças territoriais e espirituais [...].

(Salazar 1938: 438)

O acontecimento vivido no castelo de Almourol constituiu-se espontaneamente como o acto inaugural das futuras comemoraçôes do duplo centenário, a cumprir no ano de 1940. Os portugueses e o Mundo teriam seguramente em tal ocasião a possibilidade de testemunhar a mais pura das evocaçóes-pátrias sonhadas e forjadas pelo Chefe do Governo. 
Concluímos, pois, que o comprometimento de Oliveira Salazar foi determinante para a concretização da obra que se avizinhava. Com a sua chegada à presidência do Conselho de Ministros, em 5 de Julho de 1932, criou-se um quadro político relativamente idêntico ao pressentido na realidade italiana sob a liderança de Il Duce.

Benito Mussolini não era arquitecto de formação e nunca esteve em Portugal. No entanto, é facto que o seu sistema político e, em especial, a sua figura dominadora, foram uma referência para o regime e o ditador português. Daí, compreendermos que, postado sobre a secretária de Oliveira Salazar, Il Duce tenha ministrado, em parte, uma lição sobre o lugar da história no Nuovo Stato.

\section{BibLIOGRAFIA}

Baxa, Paul. 2010. Roads and Ruins. The Symbolic Landscape of Fascist Rome, Toronto, University of Toronto Press.

Fachinelli, Elvio. 1979. La freccia ferma. Tre tentativi di annullare il tempo, Milano, L'erba voglio.

Ferro, António. [1941]. Homens e multidões, Lisboa, Livraria Bertrand.

Guillaume, Marc. 2003. A política do património, trad. Joana Caspurro, Porto, Campo das Letras.

Muñoz, Antonio. 1932. "La via dell'Impero e la via del Mare", Capitolium, 11, pp. 521-556.

Salazar, António de Oliveira. 1938. "Discurso proferido no Castelo de Almourol", Ocidente, 3, pp. 438.

Sica, Paolo. 1981. Historia del urbanismo. El siglo XX, trad. Joaquim Hérnandez Orozco, Madrid, Instituto de Estudios de Administración Local.

Silva, Henrique Gomes da. 1931. "Comunicação com a ref. ${ }^{a}$ n. ${ }^{\circ} 589$ enviada pelo director-geral da Direcção-Geral dos Edifícios e Monumentos Nacionais ao Presidente do Conselho de Arte e Arqueologia da 1. " Circunscrição", id., Castelo de Palmela: Administração e fiscalização (Proc. ${ }^{\circ}$ : PT DGEMN:DSARH-010/185-0010, Doc. ${ }^{\circ}$ SIPA TXT.01570452 a SIPA TXT.01570454), SIPA, DGPC, Sacavém.

Silva, Henrique Gomes da. 1935. "Monumentos Nacionais - Orientação técnica a seguir no seu restauro", id., I Congresso da Uniāo Nacional: discursos, teses e comunicaçôes, Vol. IV, Lisboa, Edição da União Nacional. 


\section{Luís Miguel Correia}

Torgal, Luís Reis. 2009. Estados Novos, Estado Novo. Ensaios de história política e cultural, Coimbra, Imprensa da Universidade de Coimbra.

Zagni, Marco. 2006. "Alla ricerca della Tirrenide perduta", id., Esoterismo e Fascismo, Roma, Edizioni Mediterranee, pp. 281-292. 